\title{
Hepatitis E Virus Seroprevalence and Chronic Infections in Patients with HIV, Switzerland
}

\section{Alain Kenfak-Foguena, ${ }^{1}$ Franziska Schöni-Affolter, ${ }^{1}$ Philippe Bürgisser, Andrea Witteck, Katharine E.A. Darling, Helen Kovari, Laurent Kaiser, John-Marc Evison, Luigia Elzi, Vanina Gurtner-De La Fuente, Josef Jost, Darius Moradpour, Florence Abravanel, Jacques Izopet, ${ }^{2}$ Matthias Cavassini, ${ }^{2}$ and the Swiss HIV Cohort Study}

We screened 735 HIV-infected patients in Switzerland with unexplained alanine aminotransferase elevation for hepatitis E virus (HEV) immunoglobulin G. Although HEV seroprevalence in this population is low (2.6\%), HEV RNA can persist in patients with low CD4 cell counts. Findings suggest chronic HEV infection should be considered as a cause of persistent alanine aminotransferase elevation.

U nexplained liver enzyme elevation is frequently encountered in HIV-infected persons (1). Hepatitis E virus (HEV) can cause deranged liver function. Chronic infection with $\mathrm{HEV}$ has been reported in patients with organ transplants, treated malignancies, and HIV infection (2-7).

\section{The Study}

The aim of this study was to investigate the prevalence and role of HEV infection among participants of the Swiss HIV Cohort Study enrolled up to December 2008 who

Author affiliations: Centre Hospitalier Universitaire Vaudois and Lausanne University, Lausanne, Switzerland (A. Kenfak-Foguena, P. Bürgisser, K.E.A. Darling, D. Moradpour, M. Cavassini); Data Center of the Swiss HIV Cohort Study, Lausanne (F. SchöniAffolter); Cantonal Hospital St. Gallen, St. Gallen, Switzerland (A. Witteck); University of Zurich, Zurich, Switzerland (H. Kovari); University Hospital Geneva, Geneva, Switzerland (L. Kaiser); Inselspital Klinik und Poliklinik für Infektiologie, Bern, Switzerland (J.-M. Evison); Universitätsspital Klinik für Infektiologie, Basel, Switzerland (L. Elzi); Ospedale Civico Servizio Malattie Infettive, Lugano, Switzerland (V. Gurtner-De La Fuente); Klinik Im Park, Zurich (J. Jost); and Centre Hospitalier Universitaire de Toulouse, Toulouse, France (F. Abravanel, J. Izopet)

DOI: $10.3201 /$ eid1706.101067 had persistent elevated alanine aminotransferase (ALT) levels. Patients were eligible if they fulfilled the following criteria: 1 ) $\geq 18$ years of age; 2 ) history of $\geq 2$ consecutively elevated ALT values (>60 IU/L); and 3) negative for both hepatitis B antigen and hepatitis C virus antibody. Serum HEV immunoglobulin (Ig) G was detected by an enzyme immunoassay (EIA), the MP Diagnostics HEV ELISA Kit (MP Biomedicals, formerly Genelabs Diagnostics, Singapore). Positive samples were retested, and only those with a repeated positive result were considered positive. HEV RNA was determined in plasma by real-time PCR of a 189-bp product located in the open reading frame 2 region. Strains were sequenced and compared with reference HEV strains (GenBank) as described earlier (8).

For all patients meeting inclusion criteria, HEV serology was performed on the most recently stored blood sample. When available, for patients with positive serologic test results, HEV serology and blood HEV real-time PCR were performed on plasma samples stored 3 months before the first documented elevated ALT value. In these patients, HEV PCR was also performed on samples stored at the time of, and 3 months after, the first elevated ALT level.

To exclude occult infection, HEV PCR analysis was also performed on all available samples from IgG-negative patients with $<150 \mathrm{CD} 4$ cells $/ \mathrm{mm}^{3}$ at the time of initial ALT elevation. To characterize more fully the patients with positive PCR, additional serologic testing was performed by using EIAgen HEV IgG and EIAgen HEV IgM kits (Adaltis Ingen, Paris, France).

Of 15,713 patients in the database, 2,000 patients had persistently elevated ALT values. Of these, 1,256 patients who were co-infected with hepatitis B virus or hepatitis C virus and 9 with missing data were excluded; 735 patients met the inclusion criteria (Table 1). IgG serologic tests were performed at a mean of 2.1 years after the first ALT elevation, and results were positive for 19 patients $(2.6 \%)$. HEV-seropositive patients were more often female $(p=$ $0.059)$ and of Asian origin $(p=0.007)$. In the univariate analysis, presence of HEV IgG was not associated with age, route of infection, lowest CD4 count, viral load, body mass index, or ALT values (Table 1). However, age- and gender-adjusted multivariate logistic regression analysis, with HEV IgG status as the outcome variable, yielded significant odds ratios for patients with low CD4 counts compared with patients with higher CD4 counts. Patients whose lowest CD4 counts were $100-350$ cells $/ \mathrm{mm}^{3}$ were 4.7 times more likely to be HEV positive compared with those with lowest CD4 counts $<100$ cells $/ \mathrm{mm}^{3}$ (Table 2).

In 16 of the $19 \mathrm{HEV}$ seropositive patients, additional samples were available a median of 6.6 months (interquartile

${ }^{1}$ These authors contributed equally to this article.

${ }^{2}$ These authors contributed equally to this article. 
range [IQR] 4.5-6.0) before the first ALT elevation. Seroconversion from a prior negative to a positive result was found in 5 of these 16 patients $(31.3 \%)$. There were no significant differences in ALT values (median, interval between and during high ALT periods), CD4 count, or HIV viral load of those who exhibited HEV seroconversion compared to those who did not.
Real-time PCR for HEV RNA was positive in 1 of the $19 \mathrm{HEV}$ IgG-positive patients (genotype 3b), with presence of HEV RNA over a 24-month period, while HEV IgG remained negative for the first 12 months. This 46-year-old white man, who had sex with men (MSM) and received a diagnosis of HIV infection in June 2001, started highly active antiretroviral therapy (HAART) with a CD4

\begin{tabular}{|c|c|c|c|c|}
\hline Characteristic & $\begin{array}{c}\text { No. (\%) all participants, } \\
\mathrm{N}=735\end{array}$ & $\begin{array}{c}\text { No. (\%) HEV negative, } \\
n=716\end{array}$ & $\begin{array}{c}\text { No. (\%) HEV positive, } \\
n=19\end{array}$ & $\mathrm{p}$ value \\
\hline Sex & & & & 0.0587 \\
\hline M & $618(84.1)$ & $605(84.5)$ & $13(68.4)$ & \\
\hline $\mathrm{F}$ & $117(15.9)$ & $111(15.5)$ & $6(31.6)$ & \\
\hline Ethnic group & & & & $<0.0001$ \\
\hline White & $607(82.6)$ & $594(83.0)$ & $14(73.7)$ & \\
\hline Black & $70(9.5)$ & $69(9.6)$ & $1(5.3)$ & \\
\hline Hispanic & $26(3.5)$ & $25(3.5)$ & $1(5.3)$ & \\
\hline Asian & $29(3.9)$ & $26(3.6)$ & $3(15.8)$ & \\
\hline Other & $3(0.4)$ & $2(0.28)$ & $1(0.14)$ & \\
\hline Probable route of HIV infection & & & & NS \\
\hline Heterosexual & $291(39.6)$ & $283(39.5)$ & $8(42.1)$ & \\
\hline MSM & $411(55.9)$ & $400(55.9)$ & $11(57.9)$ & \\
\hline IDU & $4(0.6)$ & $4(0.6)$ & 0 & \\
\hline Blood & $5(0.7)$ & $5(0.7)$ & 0 & \\
\hline Unknown/other & $24(3.2)$ & $24(3.4)$ & 0 & \\
\hline Current or past IDU & & & & NS \\
\hline Yes & $14(2.3)$ & $14(2.0)$ & 0 & \\
\hline No & $721(99.7)$ & $702(98.0)$ & $19(100.0)$ & \\
\hline Prison history & & & & NS \\
\hline Yes & $45(6.1)$ & $44(6.1)$ & $1(5.3)$ & \\
\hline No & $690(93.9)$ & $672(93.9)$ & $18(94.7)$ & \\
\hline Alcohol consumption & & & & NS \\
\hline Yes & $261(35.5)$ & $256(35.8)$ & $5(26.3)$ & \\
\hline No & $474(64.5)$ & $460(64.2)$ & $14(73.7)$ & \\
\hline BMI group, $\mathrm{kg} / \mathrm{m}^{2}$ & & & & NS \\
\hline$\leq 25$ & $408(55.5)$ & $398(55.6)$ & $10(52.6)$ & \\
\hline $25.1-30$ & $231(31.4)$ & $225(31.4)$ & $6(31.6)$ & \\
\hline$>30$ & $96(13.1)$ & $93(12.9)$ & $3(15.8)$ & \\
\hline ALT peak value, IU/L & & & & NS \\
\hline$\leq 180$ & $606(82.4)$ & $591(82.5)$ & $15(78.95)$ & \\
\hline$>180$ & $129(17.6)$ & $125(17.5)$ & $4(21.05)$ & \\
\hline Lowest CD4 count, cells $/ \mathrm{mm}^{3}$ & & & & 0.0685 \\
\hline$<100$ & $276(37.6)$ & $273(38.1)$ & $3(15.8)$ & \\
\hline $100-350$ & $288(39.2)$ & $276(38.6)$ & $12(63.2)$ & \\
\hline$>350$ & $171(23.2)$ & $167(23.3)$ & $4(21.1)$ & \\
\hline HAART history & & & & NS \\
\hline Yes & $610(83.0)$ & $595(75.4)$ & $15(78.9)$ & \\
\hline No & $125(17.0)$ & $121(16.9)$ & $4(21.6)$ & \\
\hline Cancer occurrence & & & & NS \\
\hline Yes & $25(3.4)$ & $24(3.4)$ & $1(5.3)$ & \\
\hline No & $710(96.6)$ & $692(94.6)$ & $18(94.7)$ & \\
\hline Outcome & & & & NS \\
\hline Dead & $29(3.9)$ & $28(3.9)$ & $1(5.3)$ & \\
\hline Alive & $652(88.7)$ & $638(89.1)$ & $14(73.7)$ & \\
\hline Lost to follow-up & $54(7.4)$ & $50(7.0)$ & $4(21.1)$ & \\
\hline
\end{tabular}

*HEV, hepatitis E virus; MSM, men who have sex with men; IDU, intravenous drug use; BMI, body mass index; ALT, alanine aminotransferase; HAART, highly active antiretroviral therapy; NS, not significant. 


\section{DISPATCHES}

Table 2. Logistic regression derived odds ratios/estimates for positive HEV serology in study of prevalence and role of HEV infection among participants in the Swiss HIV Cohort Study, Switzerland, 2008*

\begin{tabular}{lcc}
\hline Variable & Odds ratio $(95 \% \mathrm{Cl})$ & $\mathrm{p}$ value \\
\hline Male vs. female & $0.207(0.041-1.016)$ & 0.0523 \\
CD4 $100-350$ vs. CD4 $<100 \mathrm{per} \mathrm{mm}^{3}$ & $4.683(1.268-17.295)$ & 0.0206 \\
CD4 $\geq 350$ vs. CD4 <100 per mm ${ }^{3}$ & $2.448(0.522-11.468)$ & 0.256 \\
Other ethnicity vs. Asian ethnicity & $0.295(0.073-1.191)$ & 0.0864 \\
Alcohol history, no vs. yes & $1.802(0.582-5.581)$ & 0.3071 \\
Risk group, other vs. MSM & $0.422(0.100-1.774)$ & 0.2392 \\
Age at ALT elevation & $1.017(0.966-1.070)$ & 0.5257 \\
Duration of ALT elevation & $1.001(1.000-1.002)$ & 0.0207 \\
\hline *HEV, hepatitis E virus; MSM, men who have sex with men; ALT, alanine aminotransferase. & \\
\hline
\end{tabular}

count of 34 cells $/ \mathrm{mm}^{3}(5 \%)$ and a normal ALT level. ALT level increased 1 month later, but HAART was continued because the patient was asymptomatic. The patient refused a liver biopsy. Real-time PCR for HEV RNA was performed between August 2001 and December 2004. HEV PCR became negative for the virus when the CD4 count reached 83 cells $/ \mathrm{mm}^{3}(17.5 \%)$, and ALT levels became normal 6 months later, when the CD4 count exceeded 100 cells $/ \mathrm{mm}^{3}$. Figure 1 shows the course of ALT values, CD4 counts, and HIV and HEV plasma viral load.

Given the prolonged viremia and late seroconversion (IgG) observed in patients with low CD4 counts, we performed real-time PCR for HEV RNA on 135 samples obtained from $54 \mathrm{HEV}$ IgG-negative patients with low CD4 counts $\left(<150\right.$ cells $\left./ \mathrm{mm}^{3}\right)$ at the time of initial ALT elevation. Real-time PCR for HEV was positive in $1 \mathrm{HEV}$ IgG-negative patient over a 5-month period (Figure 2). This 59-year-old MSM started HAART in October 1996 with a CD4 count of 140 cells $/ \mathrm{mm}^{3}$. CD4 counts remained $<250$ cells $/ \mathrm{mm}^{3}$ over the subsequent 12 years. Real-time PCR for HEV RNA was performed between March 2002 and April 2008. HEV-positive samples (genotype 3c) were identified between October 2005 and March 2006. Additional serologic analysis revealed the presence of $\mathrm{IgM}$ over a 7-month period following first positive real-time PCR but absence of IgG seroconversion.

\section{Conclusions}

This study of participants of the Swiss HIV Cohort Study shows a $2.6 \%(19 / 735)$ seroprevalence of HEV in $\mathrm{HIV}$-infected patients without $\mathrm{HBV}$ or $\mathrm{HCV}$ infection with a history of persistently elevated ALT level. We did not find higher HEV prevalence in subgroups previously considered at higher risk of HEV infection such as MSM, injection drug users, and prisoners. The prevalence in Switzerland is lower than in other European countries and the United States (9). It is now well established that pigs and other animal species constitute reservoirs for $\mathrm{HEV}$ and that transmission in industrialized countries occurs mainly through contaminated meat. We hypothesize that strict regulation of animal imports in Switzerland (10) may reduce HEV prevalence among farm animals. Food preferences and possible regional factors may also contribute to the differences between countries and merit further study.

We observed anti-HEV seroconversion in 5 patients, including one with prolonged HEV RNA $(>24$ months). In this single patient, who had a very low CD4 count, seroconversion ( $\mathrm{IgG})$ was delayed until immune reconstitution occurred. As the CD4 count exceeded 100 cells $/ \mathrm{mm}^{3}$, HEV RNA cleared, and ALT levels became normal (Figure 1). According to a literature search, 7 realtime PCR documented cases of HEV have been reported $(3,4,11-14)$. Of these, 5 case-patients with CD4 counts

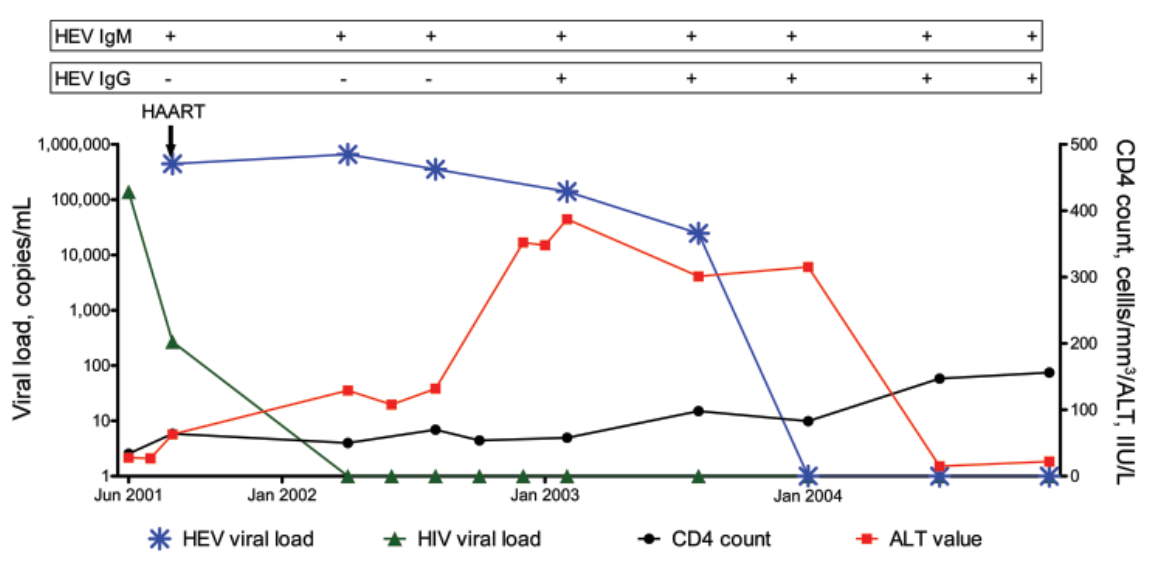

Figure 1. Longitudinal description of blood hepatitis $E$ virus (HEV) serology, HEV RNA, alanine aminotransferase (ALT) levels, HIV RNA, and CD4 count in patient with chronic HEV infection, positive results by real-time PCR for HEV RNA, and seroconversion to immunoglobulin (lg) G. HAART, highly active antiretroviral therapy. 


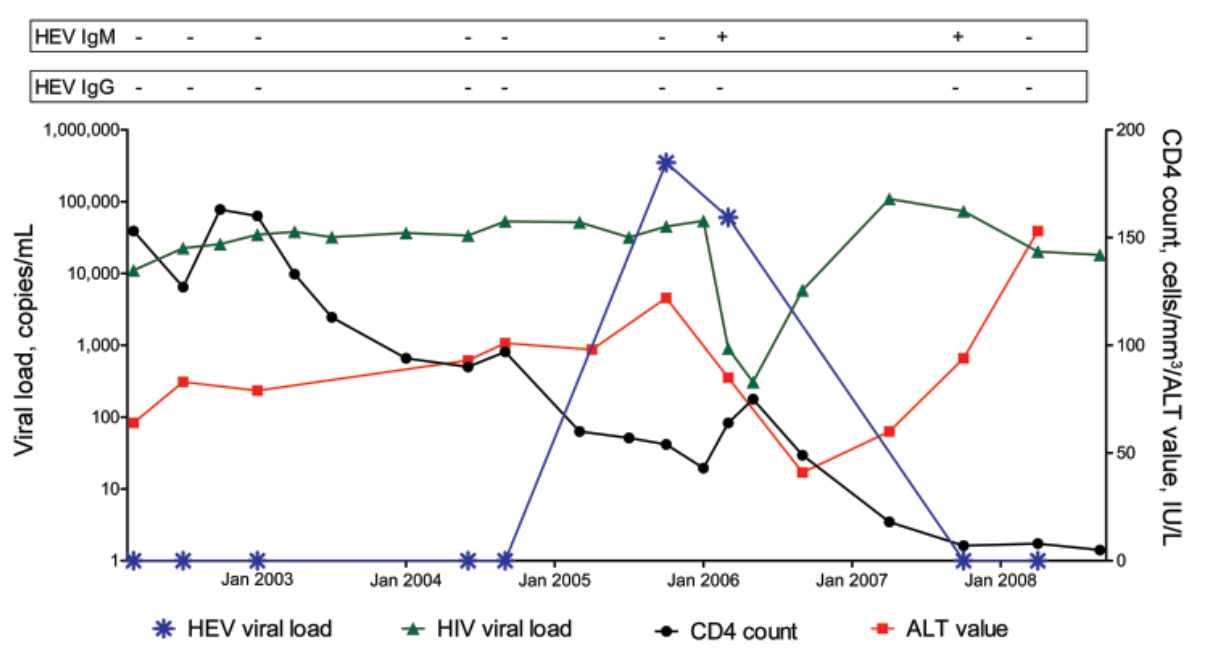

Figure 2. Longitudinal description of blood hepatitis $E$ virus (HEV) serology, HEV RNA, alanine aminotransferase (ALT) levels, HIV RNA, and CD4 count in patient with positive real-time PCR results for HEV infection but without serologic seroconversion to immunoglobulin (Ig) G.

$>200$ cells $/ \mathrm{mm}^{3}$ sought treatment with acute infection and the virus cleared, whereas in 2 patients with $<200$ CD4 cells $/ \mathrm{mm}^{3}$ persistent hepatitis developed (as we observed in our patient).

This study faced 2 common limitations regarding HEV diagnosis and comparability of seroprevalence: lack of an approved algorithm and variability of serologic tests in terms of sensitivity and specificity. According to a recent comparative study, the test used in our study may underestimate seroprevalence because of its inherent lower sensitivity (15). Moreover, the sensitivity of EIA tests among immunosuppressed patients is unknown and may be limited. We therefore screened all HEV IgG-negative patients (using HEV real-time PCR) with low CD4 counts at the time of unexplained, elevated ALT level and identified 1 patient who had 2 positive samples over a 5-month period. Unfortunately, later samples were not available to determine the precise duration of HEV viremia.

Taken together, our results suggest that serologic screening alone may be insufficient to diagnose HEV infection in HIV-infected patients with very low CD4 counts because seroconversion (IgG) may be delayed or not occur. When investigating unexplained, elevated ALT level in HIV-infected patients, we propose that HEV infection should be considered.

This study was financed within the framework of the Swiss HIV Cohort Study supported by the Swiss National Science Foundation.

Dr Kenfak-Foguena is a physician and trainee in Infectious Diseases at the University Hospital of Lausanne and works with the French National AIDS Research Agency team in Yaoundé, Cameroon. His interests include clinical research among HIV patients (viral hepatitis and opportunistic infections) and HIV treatment in resource-limited settings.

\section{References}

1. Kovari H, Ledergerber B, Battegay M, Rauch A, Hirschel B, Foguena AK, et al. Incidence and risk factors for chronic elevation of alanine aminotransferase levels in HIV-infected persons without hepatitis B or C virus co-infection. Clin Infect Dis. 2010;50:502-11. doi:10.1086/649922

2. Banas B, Tausch U, Hofstädter F, Woenckhaus M, Pietrzyk MC, Riegger GAJ, et al. Infection with hepatitis E virus: first report of a chronic case and molecular characterization of the virus. J Clin Virol. 2006;36:S162. doi:10.1016/S1386-6532(06)80503-2

3. Colson P, Kaba M, Moreau J, Brouqui P. Hepatitis E in an HIVinfected patient. J Clin Virol. 2009;45:269-71. doi:10.1016/j. jev.2009.06.002

4. Dalton HR, Bendall RP, Keane FE, Tedder RS, Ijaz S. Persistent carriage of hepatitis $\mathrm{E}$ virus in patients with HIV infection. N Engl $\mathrm{J}$ Med. 2009;361:1025-7. doi:10.1056/NEJMc0903778

5. Haagsma EB, van den Berg AP, Porte RJ, Benne CA, Vennema $\mathrm{H}$, Reimerink $\mathrm{JH}$, et al. Chronic hepatitis E virus infection in liver transplant recipients. Liver Transpl. 2008;14:547-53. doi:10.1002/ 1t. 21480

6. Kamar N, Selves J, Mansuy JM, Ouezzani L, Peron JM, Guitard J, et al. Hepatitis $\mathrm{E}$ virus and chronic hepatitis in organ-transplant recipients. N Engl J Med. 2008;358:811-7. doi:10.1056/NEJMoa0706992

7. Tamura A, Shimizu YK, Tanaka T, Kuroda K, Arakawa Y, Takahashi K, et al. Persistent infection of hepatitis E virus transmitted by blood transfusion in a patient with T-cell lymphoma. Hepatol Res. 2007;37:113-20. doi:10.1111/j.1872-034X.2007.00024.x

8. Legrand-Abravanel F, Mansuy JM, Dubois M, Kamar N, Peron JM, Rostaing L, et al. Hepatitis E virus genotype 3 diversity, France. Emerg Infect Dis. 2009;15:110-4. doi:10.3201/eid1501.080296

9. Pavio N, Mansuy JM. Hepatitis E in high-income countries. Curr Opin Infect Dis. 2010;23:521-7. doi:10.1097/QCO.0b013e32833de683

10. Swiss Federal Veterinary Office. Ordonnance du 18 avril 2007 concernant l'importation, le transit et l'exportation d'animaux et de produits animaux (OITE) [cited 2009 May 1]. http://www.admin.ch/ $\mathrm{ch} / \mathrm{f} / \mathrm{rs} / 9 / 916.443 .10$.fr.pdf.

11. Colson P, Dhiver C, Gerolami R. Hepatitis E virus as a newly identified cause of acute viral hepatitis during human immunodeficiency virus infection. Clin Microbiol Infect. 2008;14:1176-80. doi:10.1111/j.1469-0691.2008.02102.x

12. Curry JA, Adams N, Crum-Cianflone NF. Acute hepatitis E virus infection in an HIV-infected person in the United States. Ann Intern Med. 2009;150:226-7. 
13. Thoden J, Venhoff N, Miehle N, Klar M, Huzly D, Panther E, et al. Hepatitis $\mathrm{E}$ and jaundice in an HIV-positive pregnant woman. AIDS 2008;22:909-10. doi:10.1097/QAD.0b013e3282f7cb9a

14. Renou C, Lafeuillade A, Cadranel JF, Pavio N, Pariente A, Allegre $\mathrm{T}$, et al. Hepatitis $\mathrm{E}$ virus in HIV-infected patients. AIDS. 2010;24:1493-9. doi:10.1097/QAD.0b013e32833a29ab
15. Bendall R, Ellis V, Ijaz S, Ali R, Dalton H. A comparison of two commercially available anti-HEV IgG kits and a re-evaluation of anti-HEV IgG seroprevalence data in developed countries. J Med Virol. 2010;82:799-805. doi:10.1002/jmv.21656

Address for correspondence: Matthias Cavassini, Infectious Diseases Service, Centre Hospitalier Universitaire Vaudois, 1011 Lausanne, Switzerland; email: matthias.cavassini@chuv.ch

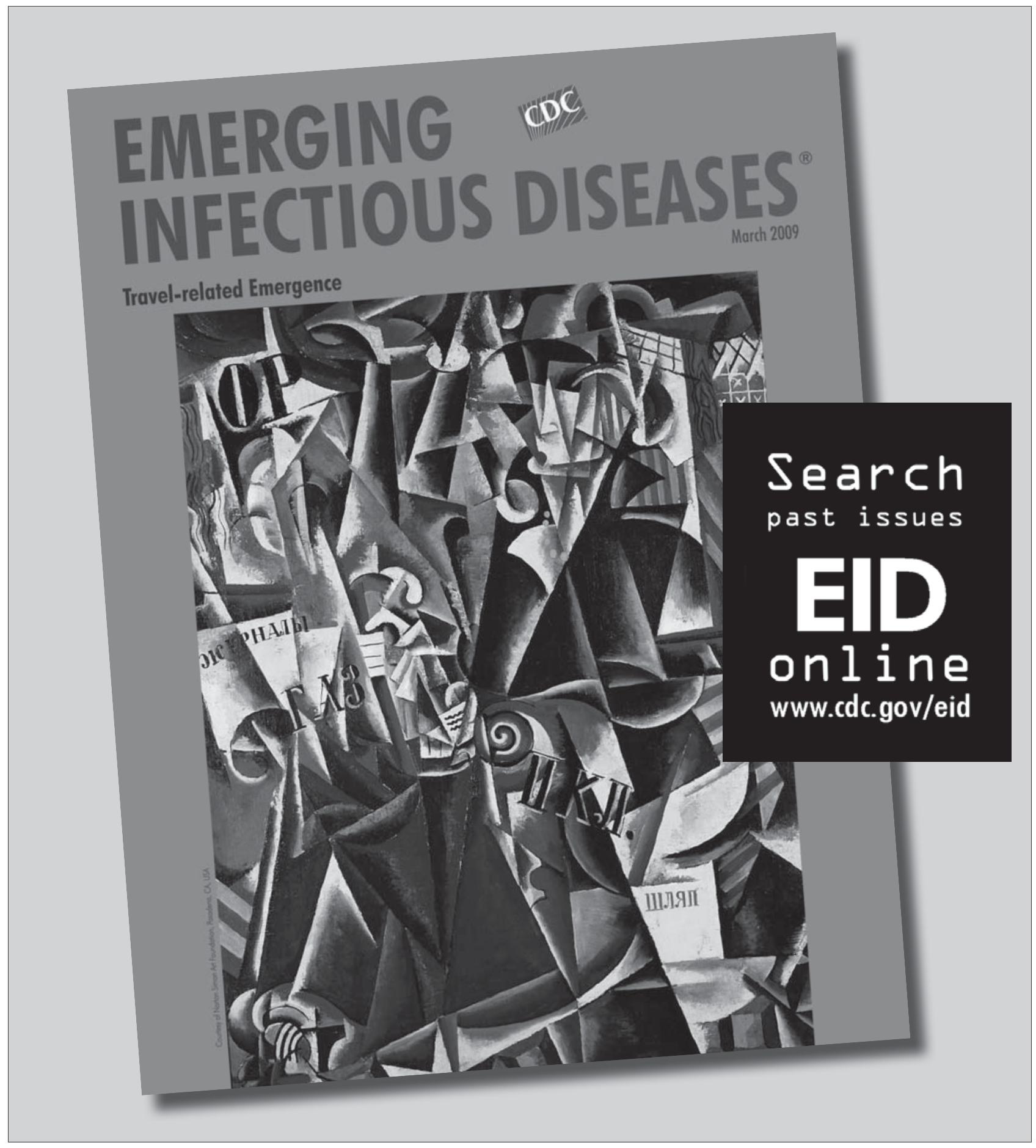

